\title{
Influencing Exit Choice in the Event of a Fire Evacuation
}

\author{
DANIEL NILSSON, HÅKAN FRANTZICH, and WENDY SAUNDERS \\ Department of Fire Safety Engineering and Systems Safety \\ Lund University \\ Box 118, SE-22100 Lund, Sweden
}

\begin{abstract}
Unannounced evacuations were performed in both an office building and a cinema theatre in order to investigate if green flashing lights at exits can influence exit choice. Also studied was how the exits were perceived and the results were interpreted using the theory of affordances. The results indicate that green flashing lights can be used to influence exit choice in the event of a fire emergency. However, the effectiveness of the system seems to depend on the setting, e.g., the type of building. The results suggest that green flashing lights at an emergency exit, if used in an appropriate setting, makes the exit stand out and encourages people to use it.
\end{abstract}

KEYWORDS: human behaviour, egress, emergency evacuation, exit choice, green flashing lights, theory of affordances.

\section{INTRODUCTION}

In the event of a fire emergency it is often essential that people use emergency exits in order to reach a safe place quickly. However, fire accidents and evacuation experiments have shown that people often use familiar exits instead of more unfamiliar emergency exits [1,2,3]. A familiar exit can be for example the entrance of a building or the ordinary exit.

One possible way to influence exit choice is to install way-guidance systems. Many different types of systems for directing people have been suggested for both smoke logged $[4,5,6,7]$ and clear fire conditions $[8,9]$. A way-guidance system that has been evaluated in many studies is flashing lights at exits $[7,8,9]$. However, previous studies have been either questionnaire studies or experiments with informed participants, i.e., participants who knew that they were taking part in an experiment. Although these studies have provided valuable information about the system, such as the influence of different colours of the flashing lights [9], they have inherent limitations. It is therefore relevant to test flashing lights at exits in realistic scenarios (in experiments with participants who have not been informed about the evacuation beforehand). These types of experiments should ideally provide a realistic estimate of the effectiveness of the system.

Previous research has suggested that the design of an exit can influence how often it is used. One example is an experiment performed at an IKEA store by Frantzich [3]. In Frantzich's experiment some emergency exits were used more frequently than others because they were placed along the extension of the walking path as opposed to at a ninety degree angle. The example illustrates that the design, in this case the location, is an important factor that should not be ignored.

A theory that is useful for analyzing exit design is the theory of affordances introduced by Gibson [10]. Gibson used the theory as a way of explaining how individuals perceive things they see. An affordance is what the object offers the individual in relation to the fulfilment of their goal. If a person's goal is to get from A to B an asphalt road affords both running and walking, but a swamp barely affords walking. One goal (of possibly many) in the event of a fire emergency is to escape. Emergency exits should therefore provide affordances that support escape, e.g., should be clearly marked, distinguishable from the surrounding, not locked, easy to open, etc.

The theory of affordances has been applied to a number of areas that range from perception of climbing routes [11] to human-computer interaction design [12]. Over the years the theory has also been expanded to fit different disciplines. One example is the four types of affordances introduced by Hartson [12] for interaction design. Hartson divides affordances into sensory, cognitive, physical, and functional based on how they support the user. Sensory affordances support the user in sensing, e.g., seeing, something. An example of a feature that provides sensory affordance can be large letters that make a sign easy to read. 
Cognitive affordance support understanding about the observed object, e.g., how it is used or what it is used for. If an opening device of an emergency exit is complicated it may be difficult to understand how it should be used, i.e., the device does not offer the potential user sufficient cognitive affordance. Physical affordance supports physically performing something, e.g., opening or closing a door. An example of a feature that provides physical affordance is that the handle of an exit door is placed at an appropriate height. Finally, functional affordance helps the user to achieve their goal, i.e., to accomplish the task they have set out to perform. If a person wants to escape as quickly as possible a fire extinguisher although it is easy to see, understand, and operate, would not offer functional affordance. However, fire extinguishers fill an important function and would have provided appropriate functional affordance if the person's main goal was to extinguish the fire.

In order to illustrate the theory of affordances it is useful to consider a simple exit design such as the left exit in Fig. 1. There are many features of the exit that provide different types of affordances in the event of a fire emergency. Since the door is a different colour than the background it is clearly distinguishable and easy to identify. The contrast between the door and the wall can therefore be seen as a sensory affordance. Another sensory affordance is provided by the emergency exit sign, which stands out on the white wall. Given that people are familiar with the meaning of the sign it also provides cognitive affordance since it informs potential users that the door can be used to leave the building in the event of an emergency. This, however, requires that people are familiar with the meaning of the sign. Physical affordance supports performing something and is therefore difficult to derive from a picture. However, the door handle of the exit looks uncomplicated and is probably easy to use. The simple handle may therefore provide physical affordance by making the door easy to open. The exit may also provide functional affordance for a person who wants to escape given that they see, understand and can use it.
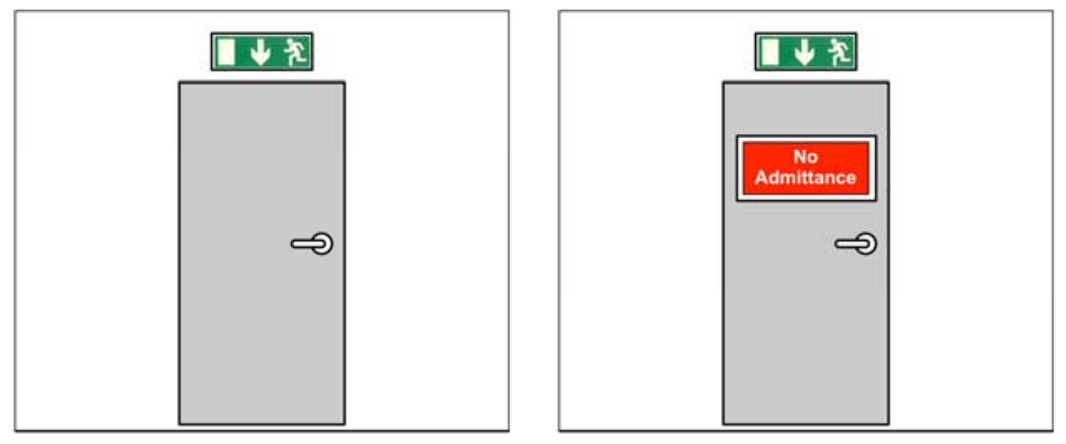

Fig. 1. An emergency exit (left) and an emergency exit with a No Admittance sign (right).

Another example of a common exit design is illustrated by the right exit in Fig. 1. The only difference between the two exits in the figure is that the right exit is also marked with a No Admittance sign since it is not supposed to be used in normal situations but only for emergency purposes. However, this simple modification may potentially change people's perception of the exit. The two signs provide conflicting cognitive affordances in the event of an emergency, namely knowledge that the exit should be used and that it should not be used. This conflict may cause uncertainty and possibly inhibit people from using the exit to escape.

Another type of conflict has been discussed by Hartson [12] who focuses mainly on situation when the cognitive affordance is not in agreement with the physical affordance provided by an object. One example is a pull handle on a door that can only be pushed open. In this case the handle provides false cognitive affordance that misinforms or misleads the user according to Hartson [12].

In this study unannounced evacuations were performed in order to study if flashing green lights can influence exit choice for realistic settings. Experiments were performed in both an office building and a cinema theatre. It was also investigated how the flashing lights influence people's perception of the exit and the results were interpreted using the theory of affordances. 


\section{EVACUATION OF AN OFFICE BUILDING}

An unannounced evacuation of an office building at AstraZeneca pharmaceutical company in Mölndal, Sweden, was performed at 10.30 on 19 May 2006. Green flashing lights at exits were used on some floors to study if the lights could influence people's choice of exit. Most participants in the experiment were familiar with the building since it was their work place.

\section{Participants}

People who took part in the evacuation consisted of employees at AstraZeneca who were in the building when the fire alarm was activated and it is estimated that 400 people took part. No information about the evacuation had been revealed beforehand. The fire alarm was activated in the entire building, but only four floors were included in the study. People who were located on other floors were hence excluded from the analysis even though they took part in the evacuation.

Based on a comparison between the video films and the questionnaires it is estimated that approximately 150 participants were on the included floors, namely floors three, four, six and seven, when the alarm was activated. However, only 98 of the participants on the four included floors filled out a questionnaire. Of these 98 people 72 were women, 25 men and one did not state gender. The average age was 45 years with a standard deviation of 10 years (five participants did not state their age in the questionnaire). Most participants worked in the building, but 26 were only attending meetings. Those participants who worked in the building had worked there between 1 month and 11 years (average of 4 years). Only 40 participants stated that they had taken part in a fire drill in the building before.

\section{The office building}

The office building has ten floors, comprising the basement, the ground floor and floors one to eight, see Fig. 2. The main entrance faces north and is located on the ground floor. In the centre of the building there is a central staircase and four elevators, which are often used to enter and exit the building. There are also two additional elevators and a staircase in the south part of the building, which are sometimes used for getting to and from the company restaurant. In addition, there are two spiral staircases called the west and east staircase that are evacuation exits from all floors to ground level. The spiral staircases are seldom used, but may sometimes be used to move between floors. All staircases are protected means of escape. Some floors are also connected to adjacent buildings to the west and east. All doors are locked and can only be opened from the outside with magnetic cards. From the inside the doors may be unlocked by pressing a button.

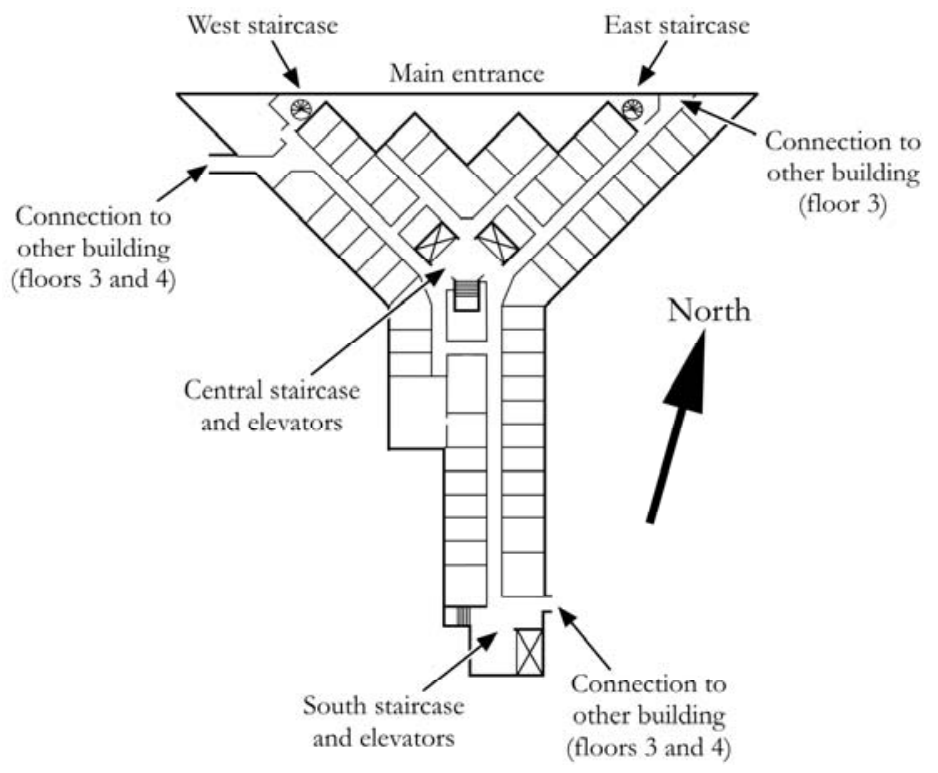

Fig. 2. A layout of the office building. 
Most floors are similar and contain mainly office spaces and meeting rooms that are connected by a network of corridors. Two pairs of floors are especially similar with regards to both interior layout and number of exits, namely floors three and four and floors six and seven. In the event of an emergency it is possible to leave floors three and four using any of the four staircases as well as connections to two other building, see Fig. 2. However, for floor three it is also possible to escape via a connection in the northeast corner of the building. For floors six and seven the only means of escape are the four staircases. Due to the similarities mentioned above only floors three, four, six and seven were included in the study.

\section{Apparatus and materials}

All evacuations were filmed with video cameras, which were placed on floors three, four, six and seven, i.e., the included floors. The cameras were put in paper bags and placed at the exits to the spiral staircases. All cameras were pointed towards the central staircase and the location provided a good overview of the sections of corridor marked in Fig. 3. In the video analysis of exit choice only those who at some point were located within the marked sections were included. This meant that participants who came from southern parts of the building and escaped directly to the central staircase were not included in the video analysis.
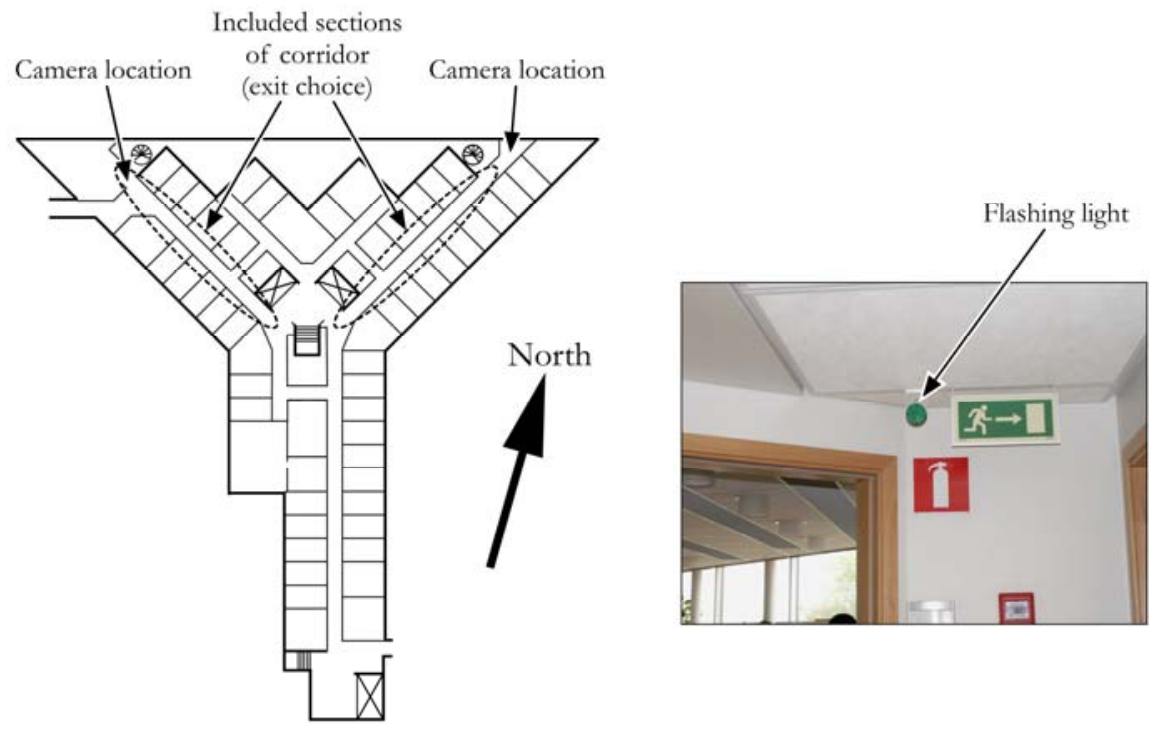

Fig. 3. The location of the cameras and the sections of corridor that were included in the analysis of exit choice (left) and a green flashing light at the west staircase (right).

The fire alarm in the building consists of bells that ring continuously until the alarm is reset. All bells are placed in the corridors. In the experiments the alarm was activated and terminated manually from the control panel on the ground floor.

One green flashing lights was used at each of the exits to the spiral staircases on floors three and seven. The light consisted of one green strobe light (xenon tube) with a diameter of 70 millimetres that was placed next to the emergency exit sign, see Fig. 3. During evacuation the lights flashed with a frequency of approximately one $\mathrm{Hz}$ (one flash per second). The lights were lit by manually flicking a switch when the alarm was activated. On the floors without flashing lights, i.e., floors four and six, there were still emergency exit sign that pointed towards the spiral staircases.

Everyone who evacuated to the gathering point in front of the main entrance was given a questionnaire. The questionnaire was divided into three parts that covered different aspects. In the first part participants were asked questions about the evacuation, namely what floor they were on, their initial location, which exit they chose, if they altered their choice of exit, what activities they were involved in prior to the alarm and what actions they undertook before starting to move towards an exit. 
The second part of the questionnaire consisted of six questions, four about the exit that was chosen and two about exits that were not chosen to leave the floor. Questions were designed to elicit affordances associated with the exits. Care was taken during formulation to avoid implicitly suggesting important factors to participants. The questions were therefore general and aimed at probing encouraging and discouraging features of the exit design. All questions could be answered by ticking either No or Yes, where the Yes alternative required that participants specified what they meant.

The four questions about the exit that participants used to leave the floor were (translated from Swedish):

1. Did the exit stand out in any way?

2. Was the exit different compared to other exits?

3. Did the appearance of the exit encourage you to use it?

4. Did the appearance of the exit discourage you from using it?

The two questions about the exits that participants did not use to leave the floor were (translated from Swedish):

5. Did you notice anything special about other exits from the floor?

6. Did the appearance of other exits influence you not to use them?

In the final part of the questionnaire participants were asked background questions, namely questions relating to gender, age, time spent working in the building and experience of fire drills in the building.

\section{Procedure}

The cameras were started and placed on the four included floors a couple of minutes before the alarm was activated. At 10.30 the alarm was started manually from the control panel on the ground floor. When the bells began to ring the green flashing lights on floors three and seven were activated manually by observers. The observers then went to the gathering point in front of the main entrance and began to distribute questionnaires to people as they exited the building.

The alarm was turned off and the people were allowed to enter the building again when it had been searched by a security guard. On their way in through the main entrance they handed in the questionnaires. Since everyone did not necessarily assemble at the gathering point the questionnaires were also sent by email to everyone in the building a couple of days after the evacuation. People who had taken part in the evacuation, but had not handed in a questionnaire were urged to hand in the questionnaire sent by email.

\section{Data analysis}

The video films were analyzed to determine which exits were used to leave floors three, four, six and seven. Only people who were located within the marked sections in Fig. 3 at some point during the evacuation were included in the analysis of exit choice. This meant that those participants who came from other parts of the building and escaped directly to the central staircase were not included. Fischer's exact test [13] was used to investigate if the proportion of participants that used the spiral staircases differed between the floors with and the floors without green flashing lights, i.e, to test if the lights influenced people's exit choice. A significance level of $5 \%$ was used, i.e., $\alpha=0.05$.

The questionnaires were sorted based on the floor location prior to the evacuation given by participants in the background questions. Only questionnaires from participants who were on floors three, four, six and seven when the fire alarm was activated were selected for further analysis. Participants' answers were used to obtain background information, e.g., age, gender, experience and use of exits for non-emergencies. An in-depth analysis of answers to the six questions about characteristics of exits was also performed. Participants who marked the Yes alternative on these questions were also asked to specify what they meant. The explanations given by participants were divided into categories according to Table 1 .

The video films were also analyzed to get an idea of what actions participants undertook before they began to move towards an exit. Further information about the action of participants was obtained from the questionnaires. 
Table 1 . The categories that were used to classify answers to the six questions about exits.

\begin{tabular}{ll}
\hline Category & Description \\
\hline Clearly marked & $\begin{array}{l}\text { The exit was clearly marked as an emergency exit or was equipped with an } \\
\text { emergency exit sign }\end{array}$ \\
Flashing light & There were flashing lights at the exit \\
Known exit & The exit was known, was the ordinary exit/entrance or was regularly used \\
Others used it & The exit was used by others (social influence) \\
Closest & Closest exit or short distance to exit \\
Big & The exit or stairs were big, wide or had a large capacity \\
Small & The exit or stairs were small, narrow or had a limited capacity \\
Crowded & Crowded or many people at the exit or in the staircase \\
Other & Other comments mentioned by less than three participants \\
\hline
\end{tabular}

\section{EVACUATION OF A CINEMA THEATRE}

Four unannounced evacuations of a cinema theatre in Lund were performed in March 2007. In two of the evacuations green flashing lights were placed at one of the two exits from the theatre in order to study if the lights could influence people's choice of exit. The participants in the experiments were not familiar with the building as they usually spend limited time in cinema theatres and furthermore have probably no experience with cinema theatre emergency evacuations.

\section{Participants}

Participants consisted of cinema visitors who had bought tickets for the shows. None of the visitors had received information about the evacuation beforehand and were hence unaware that the fire alarm was going to be activated. In one of the experiments a person exited the cinema theatre before the alarm was activated and was hence excluded from the study. The total number of participants was 49, namely 26 women and 23 men. The average age was 32 years and the standard deviation was 14 years according to the questionnaire. Participants were reimbursed with one cinema check, which allowed another visit to the cinema, after they had filled out the questionnaire.

\section{The cinema theatre}

The cinema theatre holds a maximum of 53 visitors, see Fig. 4 . There are five rows in the theatre and along the left side there are stairs from the front to the back. This means that visitors can only exit a row from one end. In front of the first row of seats there is a handrail to prevent people from falling down from the first row to the area in front of the screen.
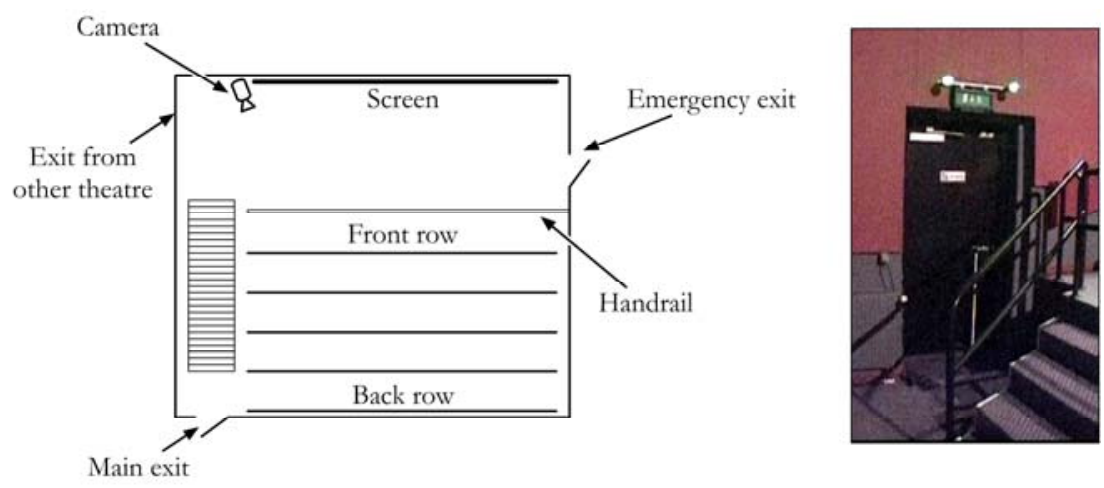

Fig. 4. A layout of the cinema theatre (left) and green flashing lights at the emergency exit (right).

Three doors connect the cinema theatre to other parts of the building or to the outside. One door, which has no handle, is located in the front left corner of the room. This door can only be opened from an adjacent 
room and can therefore not be used to exit the theatre. The door is not equipped with an emergency exit sign.

In the event of an evacuation visitors can use one of two exits, namely the main exit or the emergency exit, see Fig. 4. Both doors of the exits are black steel doors that are clearly distinguishable from the red walls of the cinema theatre. There are also standard emergency exit signs above both the main and emergency exit. The main exit leads to the ticket hall via a corridor and is also the ordinary entrance and the normal exit for non-emergency situations. This means that it is the most frequently used and therefore the one that visitors are most familiar with. The emergency exit, which is never used for non-emergency situations, leads directly to the outside. The door is equipped with a panic bar and a sign with the text Not an exit.

\section{Apparatus and materials}

All evacuations were filmed with a video camera that was located in the front left corner of the cinema theatre. The camera was concealed in a black box that was placed next to the screen at a height of two meters. The location provided a good overview of the room. All seats and the main exit were covered by the camera, but the emergency exit was not. However, from the video films it was clear which exit that was used by participants.

The fire alarm was played using the sound system in the cinema theatre and consisted of a pre-recorded message that was preceded by a pulsating tone signal. The message, which was read by a woman, consisted of a call for attention, information that a fire incident had occurred and instructions to leave through the closest exit and gather outside the building. In the experiments the alarm was activated manually from the projection room when the film had been stopped. The tone signal and the pre-recorded message were repeated until the experiment was terminated.

Green flashing lights were used at the emergency exit in two of the four experiments. The lights consisted of two green light bulbs that were placed above the emergency exit sign, see Fig. 4. During evacuation the lights flashed with a frequency of approximately one $\mathrm{Hz}$ (one flash per second). The lights were turned on manually with a remote control when the alarm was activated. In the experiments without flashing lights only the light bulbs were removed, but the emergency exit sign above the door remained.

All participants filled out a questionnaire after evacuation. The questionnaire was divided into three parts that were similar to the parts used in the questionnaire for the office building evacuation described earlier. In the first part participants were asked background questions, namely questions relating to gender and age. The second part contained questions about the evacuation, e.g., their initial location, which exit they chose, if they changed their choice of exit and actions they undertook before beginning to move towards an exit. In the third part participants were asked four questions about the exit they used and two about the exit they did not use to leave the cinema theatre. Apart from minor changes, the six questions used in part three were identical to the six questions about exits in the second part of the office building questionnaire. The main difference was that floor was replaced by cinema theatre in question five.

\section{Procedure}

The video camera was started just before the visitors were allowed to enter the cinema theatre. While visitors were entering and taking their seats advertisements were shown on the screen. After a while the advertisements came to an end and film trailers were shown instead. Towards the end of the film trailers, usually in the middle of the last trailer, the film was stopped, emergency lights were lit and the alarm was activated. The participants began to evacuate and were stopped either in the corridor outside the main exit or outside the building if they used the emergency exit. The experiment was terminated when all participants had left the cinema theatre.

In the experiments an observer was present inside the cinema theatre, namely in a seat close to the back right corner. The main purpose of the observer was to control the video camera and the flashing lights and to interrupt the experiment if something went wrong. In order to influence the reaction of others as little as possible the observer was instructed to respond when everyone else had risen from their seats and to be among the last to leave the room.

When everyone had left the alarm was turned off and the participants were led into the cinema theatre again where they were informed about the evacuation. They were also given the questionnaire, which they filled 
out while sitting in their seats. The questionnaire was collected immediately and the participants then wrote their home address on a list that was passed around. The list with addresses was only used to send a cinema check and written information about the study to participants.

A total of four evacuation experiments were performed, namely two with and two without green flashing lights at the emergency exit. Information about the experiments can be found in Table 2. The number of participants in the experiments varied between 10 and 17, i.e., only about 20 to 30 percent of the seats were taken.

Table 2. The four evacuation experiments in the cinema theatre.

\begin{tabular}{cccc}
\hline Experiment & Flashing lights & Show & Number of participants \\
\hline A & Yes & Late & $11^{\mathrm{a}}$ \\
B & Yes & Late & 11 \\
C & No & Early & 17 \\
D & No & Late & 10 \\
\hline${ }^{a}$ Excluding of
\end{tabular}

${ }^{\mathrm{a}}$ Excluding one person who left before the alarm was activated.

\section{Data analysis}

The video films were analyzed to determine which exit was used to leave the cinema theatre in the four experiments. However, no significance test was used to investigate if the use of exits differed between the experiments with and without green flashing lights. The video films were also analyzed to obtain information about actions undertaken by participants before they started to move towards an exit. Further information about participants' actions was obtained from the questionnaires.

The questionnaires were used to get background information about the participants, i.e., their age and gender. An in-depth analysis of answers to the questions about characteristics of exits was also performed. Participants could reply either No or Yes to these questions. If they answered Yes they were asked to explain what they meant. These explanations were divided into categories according to Table 1. However, the categories Big, Small and Crowded were not used since they were not relevant for the cinema theatre evacuations.

\section{RESULTS}

\section{Evacuation of an office building}

The video films show that most participants left their offices promptly, but some sought additional information before they began to move towards an exit. Examples of behaviour that indicated seeking of information was looking out through windows, looking out into the corridor and talking to colleagues. The questionnaires also substantiate that many wanted confirmation of what was happening. One quarter of the participants mentioned that they had performed actions that were aimed at getting more information. The most common action was to look for information at AstraZeneca's intranet, but some also said that they talked to colleagues or looked out through windows.

Other actions that were mentioned in the questionnaire were mainly preparative, i.e., getting ready to leave the building. Examples included logging out or turning off computers, ending phone calls, putting on additional clothes and gathering belongings. One tenth also mentioned that they tried to warn others, encourage others to escape or looked for colleagues, e.g., checked to see that the restrooms were empty.

The analysis of exit choice based on the video films revealed that a slightly larger proportion of participants used the spiral staircases when green flashing lights were used, see Table 3. The proportion of participants who used the spiral staircase was $18 \%$ for floors three and seven and $11 \%$ for floors four and six. However, this difference was not significant (Fishers exact test, $\mathrm{p}=.685$ ). The majority of participants, namely $82 \%$, also stated in the questionnaire that they used the central staircase. These results confirm observations from the evacuation, namely that the central staircase was crowded and that few used the east and west staircases. Only 49 participants were in the marked sections of corridor in Fig. 3 during evacuation and only those 49 people were hence included in the analysis of exit choice, see Table 3. 
Table 3. Use of exits in the office building evacuation.

\begin{tabular}{cccc}
\hline \multirow{2}{*}{ Floor } & \multirow{2}{*}{ Flashing lights } & \multicolumn{2}{c}{ Exit use } \\
\cline { 3 - 4 } & & Spiral staircase & Other exits \\
\hline 3 and 7 & Yes & 4 & 18 \\
4 and 6 & No & 3 & 24 \\
\hline
\end{tabular}

Participants' answers to the questions about exits were more extensive than requested. Answers not only related to the mere appearance of the exits, but also to surrounding factors such as action of others. The answers to the six questions about exits are given in Table 4 and include both participants who used the spiral staircases and those who used other exits. Answers that were given by more than four people, i.e., more than 5\% are underlined and bold in the table.

Table 4 shows that size or capacity of the exit was an important feature. Twelve participants, who all used the central staircase, wrote that the large size or large capacity were encouraging features. Also, four participants, who all used the central staircase, wrote that the small size or the limited capacity were discouraging features for other exits. Ironically, since many used the central staircase it became crowded, whereas other staircases were almost empty. The large number of people in the central staircase was also mentioned as a discouraging factor.

Relatively few mentioned the green flashing lights. Only two of the four participants who used the spiral staircases on floors with flashing light pointed out the lights. Three participants who used the central staircase also pointed out the lights. Another factor that was mentioned was the distance to the chosen exit, i.e., a short distance was perceived as an encouraging factor.

Table 4 . Answers to the six questions about exits arranged by category.

\begin{tabular}{|c|c|c|c|c|c|c|}
\hline \multirow[b]{2}{*}{ Category } & \multicolumn{4}{|c|}{$\begin{array}{c}\text { Used } \\
\text { exit }\end{array}$} & \multicolumn{2}{|c|}{$\begin{array}{c}\text { Other } \\
\text { exit }\end{array}$} \\
\hline & 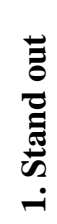 & 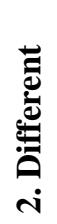 & 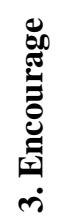 & 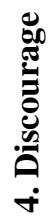 & 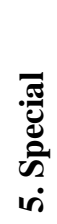 & 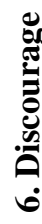 \\
\hline Clearly marked & 2 & 2 & 3 & 0 & 0 & 0 \\
\hline Flashing light & 2 & 0 & 0 & 0 & 3 & 0 \\
\hline Known exit & 1 & 0 & 4 & 0 & 0 & 0 \\
\hline Others used it & 2 & 1 & 3 & 0 & 0 & 0 \\
\hline Closest & 11 & 3 & $\mathbf{5}$ & 0 & 0 & 0 \\
\hline Big & $\overline{2}$ & 4 & $\underline{12}$ & 0 & 0 & 0 \\
\hline Small & 0 & 0 & 1 & 0 & 0 & 4 \\
\hline Crowded & $\underline{5}$ & 3 & 0 & $\underline{6}$ & 0 & 0 \\
\hline Other & $\overline{2}$ & 3 & 7 & $\overline{2}$ & 3 & 5 \\
\hline
\end{tabular}

\section{Evacuation of a cinema theatre}

The films from the evacuations revealed that participants responded promptly. Most people started to prepare to escape when the message had been played once. Typical behaviour before beginning to move towards an exit included putting on additional clothes and gathering belongings. These actions were also frequently mentioned in the questionnaires.

The importance of the green flashing lights on exit choice was apparent in the cinema theatre experiments, see Table 5. Everyone used the emergency exit in the experiments with flashing lights, whereas the emergency exit was not used at all in the experiments without flashing lights. In experiments A and D two participants initially headed towards one exit, but later turned around and used the other exit to leave the cinema theatre. 
Table 5. Use of exits in the cinema theatre evacuations.

\begin{tabular}{cccc}
\hline \multirow{2}{*}{ Experiment } & \multirow{2}{*}{ Flashing lights } & \multicolumn{2}{c}{ Exit use } \\
\cline { 3 - 4 } & & Emergency exit & Main exit \\
\hline A and B & Yes & 22 & 0 \\
C and D & No & 0 & 27 \\
\hline
\end{tabular}

Participants' answers to the questions about exits were more extensive than requested. Answers related to both the appearance of the exits as well as surrounding factors, e.g., actions of others. Table 6 shows that participants' answers to the six questions about exits for the experiments with and without green flashing lights. Answers that were given by more than three persons are underlined and bold in the table. Table 6 shows that the green flashing lights were seen as an encouraging feature that made the emergency exit stand out. It is also worth mentioning that four participants in the experiments without flashing lights wrote that a special feature of the emergency exit was that it was equipped with an emergency exit sign. However, these individuals did not mention the emergency exit sign at the main exit even though they used that exit to leave the cinema theatre and not the emergency exit.

Table 6. Answers to the six questions about exits arranged by category for experiment with and without flashing lights.

\begin{tabular}{|c|c|c|c|c|c|c|c|c|c|c|c|c|}
\hline \multirow[b]{3}{*}{ Category } & \multicolumn{6}{|c|}{ With flashing lights } & \multicolumn{6}{|c|}{ Without flashing lights } \\
\hline & \multicolumn{4}{|c|}{$\begin{array}{l}\text { Used } \\
\text { exit }\end{array}$} & \multicolumn{2}{|c|}{$\begin{array}{c}\text { Other } \\
\text { exits }\end{array}$} & \multicolumn{4}{|c|}{$\begin{array}{c}\text { Used } \\
\text { exit }\end{array}$} & \multicolumn{2}{|c|}{$\begin{array}{l}\text { Other } \\
\text { exits }\end{array}$} \\
\hline & 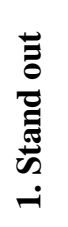 & 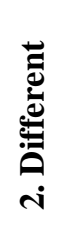 & 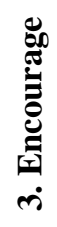 & 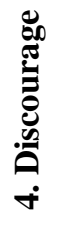 & 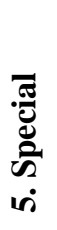 & 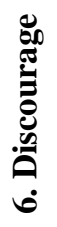 & 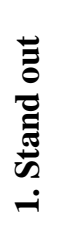 & 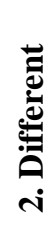 & 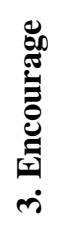 & 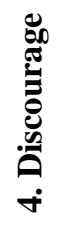 & $\begin{array}{l}\text {. } \\
\text { के } \\
\text { के } \\
\text { के }\end{array}$ & 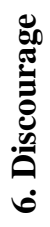 \\
\hline Clearly marked & 3 & 1 & 2 & 0 & 0 & 0 & 3 & 0 & 0 & 0 & 4 & 0 \\
\hline Flashing light & $\underline{20}$ & $\underline{14}$ & $\underline{15}$ & 0 & 0 & 0 & 0 & 0 & 0 & 0 & 0 & 0 \\
\hline Known exit & $\overline{0}$ & $\overline{0}$ & $\overline{0}$ & 0 & 0 & 0 & 2 & 3 & 0 & 0 & 0 & 0 \\
\hline Others used it & 0 & 0 & 1 & 0 & 0 & 0 & 3 & 0 & 1 & 0 & 0 & 0 \\
\hline Closest & 0 & 0 & 0 & 0 & 0 & 0 & 2 & 3 & 0 & 0 & 0 & 0 \\
\hline Other & 1 & 3 & 4 & 1 & 3 & 3 & 2 & 0 & 1 & 1 & 1 & 3 \\
\hline
\end{tabular}

\section{DISCUSSION}

In the present study evacuations were performed in two settings, namely an office building and a cinema theatre. These two settings differ in many ways, but one of the most important differences is the familiarity with the building. The occupants of an office building typically know the building quite well since they spend considerable time there. Cinema visitors on the other hand are less familiar with the cinema theatre since they spend quite limited time there.

In the office building emergency exits were chosen slightly more frequently if green flashing lights were used, but the difference was not significant. Also, the lights were mentioned by only a few participants, which suggest that they were either not perceived as important features of the exits or were not noticed at all. It is believed that the latter explanation is the most likely, i.e., that the flashing lights were not noticed, as the green strobe lights (xenon tube) that were used in the brightly lit corridors probably did not provide enough contrast and thus not sufficient sensory affordance to be noticed by participants. It is therefore recommended that similar experiments are performed with more powerful lights.

Because the lights did not provide sufficient sensory affordance other factors most likely became more important. The fact that the participants were familiar with the office building probably influenced what features of the exits were identified. Many mentioned the size or capacity of the stairs as important factors. The large capacity of the central staircase was encouraging and the limited capacity of other staircases was 
discouraging. These factors are actually not part of an exit's exterior appearance, but instead require knowledge about what lies behind the door, i.e., familiarity with the building. Ironically, the large size probably influenced many participants to use the central staircase, which lead to crowding and unnecessarily long evacuation times. It would have been better if people used other exits to a greater extent, which may be possible to achieve with more appropriate lights at the exits.

The potential effectiveness of green flashing lights for influencing exits choice was clearly demonstrated by the cinema theatre evacuations. Almost all participants mentioned the flashing lights as a feature of the exit that made it stand out, which suggests that the system provided sufficient sensory affordance. Many also mentioned that the flashing lights also encouraged people to use the exit, which can be a result of cognitive affordances introduced by the system. The system possibly signals a change from passive to active, since the lights begin to flash when the alarm is activated. This transition may help potential users to understand that the exit is now available for use and that it is allowed to use it.

The experiments pose an interesting question: How important is the colour of the flashing lights? In the experiments only green lights were tested, but previous studies suggests that the colour can be of great importance [7,9]. Some colours are known to have established meanings within populations [14]. Red is often associated with stop or danger, whereas green is often associated with go or safety. These established meanings of colours can potentially cause conflicting cognitive affordances. Although red flashing lights at an exit can provide powerful sensory affordance, the colour may tell potential users that they should keep away. This information is in conflict with the sign that instructs people to use the exit in the event of an emergency. However, use of colours must be seen in the context of culture, since the established meanings may differ between populations.

In this study focus has been on the appearance of exits and more specifically on how green flashing lights influence people's perception of exits. However, results indicate that there are many other factors not related to exit design that influence exit choice during evacuation. One example of an important factor is the actions of others, i.e., social influence. If someone begins to use an exit it is probable that others will follow and that flashing lights or other types of systems may not be sufficient to convince people to change their choice of exit. However, the appearance of exits is undoubtedly important when people decide what exits to use in the event of a fire emergency. Attention must therefore be focused on exit design when buildings are planned and built.

One limitation of the study is the small number of participants that took part in the cinema theatre evacuations. On average only a quarter of the seats were taken, which presumably influenced participants' exit choice. People would possibly have used both exits even if one was equipped with flashing lights if the cinema theatre was full. It is therefore suggested that more experiments with flashing lights at exits should be performed to investigate how the system influences exit choice for cinema theatres that are filled to capacity.

\section{CONCLUSIONS}

The present study suggests that green flashing lights at exits can be used to influence exit choice, but that the effectiveness of the system depends on the setting. Flashing lights, if used appropriately, make the exit stand out and encourages people to use it. One possible explanation is that the lights begin to flash when the alarm is activated, which signals a transition from passive to active. This transition can help potential users to understand that the exit is available for use.

\section{ACKNOWLEDGEMENTS}

The authors would like to thank Byggrådet (The joint cooperation between the building industry and universities) for funding the research. Special thanks also go to Kurt-Owe Roos and Elinor Andersson at AstraZeneca in Mölndal for all the help with the office building evacuation and to cinema manager Pia Andersson and the staff at SF Bio in Lund for assistance with planning and performing the cinema theatre evacuations. The experiments would not have been possible without the assistance of Sven-Ingvar Granemark, Charlotte Lindberg, Tobias Erdsjö, and Boel Reinicke and their help is much appreciated. 


\section{REFERENCES}

[1] Sime, J.D. (1985) Movement Towards the Familiar - Person and Place Affiliation in a Fire Entrapment Setting, Environment and Behaviour 17(6): 697-724, doi:10.1177/0013916585176003

[2] Shields T.J. and Boyce K.E. (2000) A Study of Evacuation from Large Retail Stores, Fire Safety Journal 35, 2000, 25-49. doi:10.1016/S0379-7112(00)00013-8

[3] Frantzich, H., "Occupant Behaviour and Response Time - Results from Evacuation Experiments," Human Behaviour in Fire - Proceedings of the Second International Symposium, Boston, USA, 2001, pp 159-165.

[4] Heskestad, A.W. (1999) Performance in Smoke of Wayguidance Systems, Fire and Materials 23(6): 375-381, doi:10.1002/(SICI)1099-1018(199911/12)23:6<375::AID-FAM714>3.0.CO;2-0

[5] Paulsen, T. "The Effect of Escape Route Information on Mobility and Way Finding Under Smoke Logged Conditions," Fire Safety Science - Proceedings of the Fourth International Symposium, Ottowa, Canada, 1994, pp 693-704.

[6] Jin, T. and Yamada, T. "Experimental Study on Effect of Escape Guidance in Fire Smoke by Travelling Flashing of Light Sources," Fire Safety Science - Proceedings of the Fourth International Symposium, Ottowa, Canada, 1994, pp 705-714.

[7] Frantzich, H. and Nilsson, D., "Evacuation Experiments in a Smoke Filled Tunnel," Human Behaviour in Fire - Proceedings of the Third International Symposium, Belfast, UK, 2004, pp 229-238.

[8] Mc Clintock, T., Shields, T.J., Reinhardt- Rutland, A.H. and Leslie, J.C., A Behavioural Solution to the Learned Irrelevance of Emergency Exit Signage, Human Behaviour in Fire - Proceedings of the Second International Symposium, Boston, USA, 2001, pp 23-33.

[9] Nilsson, D., Frantzich, H. and Saunders, W., "Coloured Flashing Lights to Mark Emergency Exits - Experiences from Evacuation Experiments," Fire Safety Science - Proceedings of the Eighth International Symposium, Beijing, China, 2005, pp 569-579.

[10] Gibson, J. J., The Ecological Approach to Visual Perception, Houghton Mifflin Company, Boston, 1978.

[11] Boschker, M.S.J., Bakker, F.C., and Michaels, C.F. (2002) Memory for the Functional Characteristics of Climbing Walls: Perceiving Affordances, Journal of Motor Behaviour 34(1): 25-36

[12] Hartson, H.R. (2003) Cognitive, Physical, Sensory and Functional Affordances in Interaction design, Behaviour \& Information Technology 22(5): 315-338, doi:10.1080/01449290310001592587

[13] Gopal, K.K., 100 Statistical Tests $-3^{\text {rd }}$ Edition, SAGE Publications Ltd, London, 2006.

[14] Wickens, C.D. and Hollands, J.G., Engineering Psychology and Human Performance, Prentice Hall, New Jersey, 2000. 